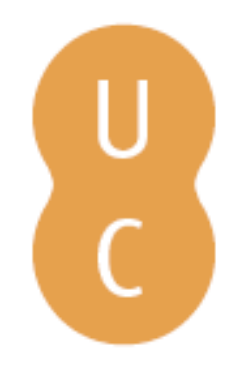

\title{
nombalina
}

\section{Representações da patologia feminina na psiquiatria portuguesa (1950-1960)}

Autor(es): $\quad$ Roque, Maria Helena Neves

Publicado por: Imprensa da Universidade de Coimbra

URL

persistente: URI:http://hdl.handle.net/10316.2/32420

DOI: $\quad$ DOI:http://dx.doi.org/10.14195/978-989-26-0469-5_24

Accessed : $\quad$ 26-Apr-2023 14:05:51

A navegação consulta e descarregamento dos títulos inseridos nas Bibliotecas Digitais UC Digitalis, UC Pombalina e UC Impactum, pressupõem a aceitação plena e sem reservas dos Termos e Condições de Uso destas Bibliotecas Digitais, disponíveis em https://digitalis.uc.pt/pt-pt/termos.

Conforme exposto nos referidos Termos e Condições de Uso, o descarregamento de títulos de acesso restrito requer uma licença válida de autorização devendo o utilizador aceder ao(s) documento(s) a partir de um endereço de IP da instituição detentora da supramencionada licença.

Ao utilizador é apenas permitido o descarregamento para uso pessoal, pelo que o emprego do(s) título(s) descarregado(s) para outro fim, designadamente comercial, carece de autorização do respetivo autor ou editor da obra.

Na medida em que todas as obras da UC Digitalis se encontram protegidas pelo Código do Direito de Autor e Direitos Conexos e demais legislação aplicável, toda a cópia, parcial ou total, deste documento, nos casos em que é legalmente admitida, deverá conter ou fazer-se acompanhar por este aviso.

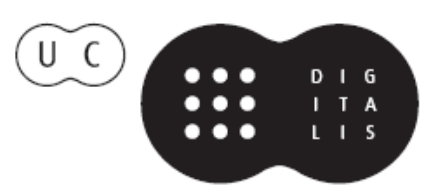


Ana Leunar Pereira João Rui Pita

[ Coordenaçä̃ ]
Rotas da Natureza

Cientistas

Viagens

Expedifgũes

Instituip̧ües

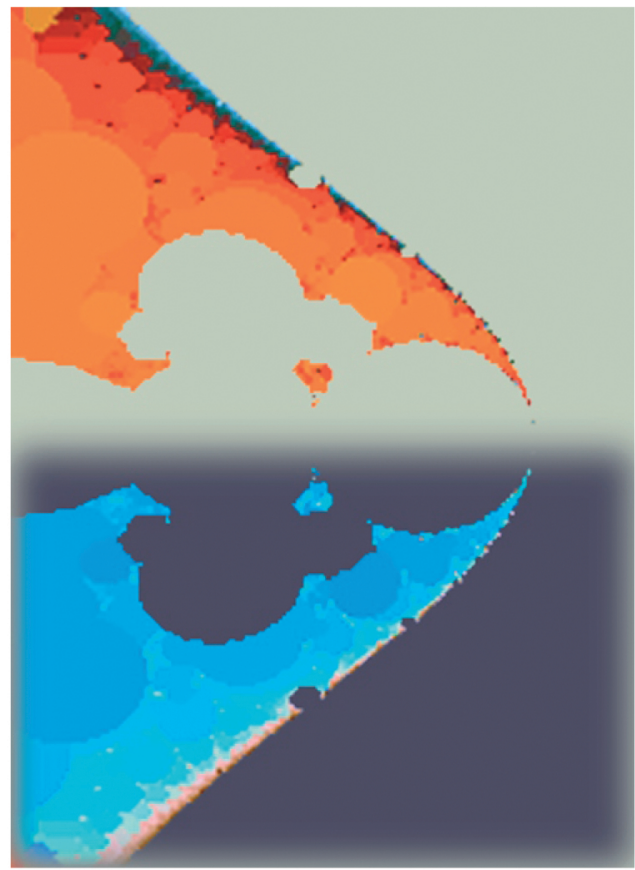




\section{Coordenaçáo Científica da Colecção Ciências e Culturas}

João Rui Pita e Ana Leonor Pereira

Os originais enviados são sujeitos a apreciação científica por referees

\section{Coordenação Editorial}

Maria João Padez Ferreira de Castro

\section{Edição}

Imprensa da Universidade de Coimbra

Email:impresauc@ci.uc.pt

URL: http://www.imp.uc.pt • Normas de publicação de colecçôes

\section{Design}

António Barros

Pré-Impressáo

António Resende

Imprensa da Universidade de Coimbra

\section{Capa}

António Barros, com imagem de E. M. de Melo e Castro, 2003 [Fractal original gerado no Fractint com tratamento no Photoshop 7.0]; Cortesia: António Barros

Impressão e Acabamento

SerSilito • Maia

\section{ISBN}

978-989-8074-12-6

\section{Depósito Legal}

Obra publicada com a colaboraçáo de:
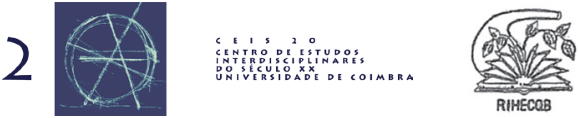

Obra publicada com o apoio de:

FCT Fundação para a Ciência e a Tecnologia

MINISTÉRIO DA CIÊNCIA, TECNOLOGIA E ENSINO SUPERTOR Portug

Programa Operacional Ciência, Tecnologia, Inovação do Quadro Comunitário de Apoio III
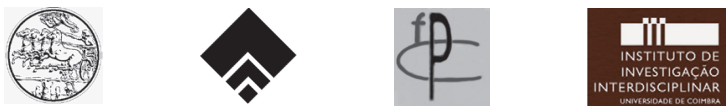

\section{Baxter}

(c) 2006, Imprensa da Universidade de Coimbra 
João Rui Pita

Ana Leonar Pereira

(Courdenação)

Rotas da Natureza

Cientistas

Viagens

Expediçũes

Instituiç̃̃es

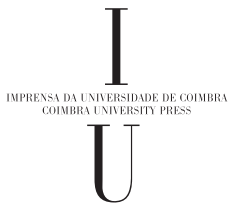

- colmbra 2006 
(Página deixada propositadamente em branco) 


\author{
Maria Helena Neves Roque \\ Centro de Investigação em História e Filosofia da Ciência \\ da Faculdade de Ciências e Tecnologia da Universidade Nova de Lisboa, Portugal
}

\author{
REPRESENTAÇÕES DA PATOLOGIA FEMININA NA \\ PSIQUIATRIA PORTUGUESA (1950-1960)
}

\title{
Introdução
}

A presente comunicação tem por finalidade analisar trabalhos de psiquiatras portugueses da década de 50, que incidem sobre o comportamento feminino, evidenciando as imagens e concepçôes da psicopatologia da mulher implícitas nos referidos textos. A análise dos artigos é estruturada em torno da articulação entre Género e Patologia, bem assim como das correlaçôes entre Ginecologia e Psiquiatria.

\section{Breve panorama da psiquiatria na década de 50}

Os anos 50 do século XX foram decisivos na história da psiquiatria devido ao surgimento de novos medicamentos, que provocaram uma profunda alteração na assistência psiquiátrica. Iniciava-se, segundo alguns autores, uma nova era revolucionária na psiquiatria. Com o aparecimento e desenvolvimento dos neurolépticos alguns dos problemas com que se defrontavam os psiquiatras foram atenuados. Robert Cancro afirma, neste sentido, que teriam ocorrido duas grandes revoluções psiquiátricas no século XX, a psicanalítica e a psicofarmacológica ${ }^{1}$.

1 «The second revolution was the psychopharmacologic. Like all revolutions, it tried to eradicate what went before it rather than to integrate and build on the past. This attitude created a lost opportunity to bring together the mentalist approach of the psychoanalyst with the biologic approach of the psychopharmacologist.» Robert Cancro, "The Introduction of Neuroleptics: A Psychiatric Revolution,» Psychiatry Serv 51,333-335, 2000, American Psychiatric Association, http://ps.psychiatryonline.org/cgi/content/full/51/3/333:. Ver também, Addison M. Duval, M. D., Washington, D. C. and Douglas Goldman, M. D., Ohio, "The New Drugs (Chlorpromazine \& Reserpine): Administrative Aspects,» Psychiatr Serv 51, 327-331, March 2000, http://ps.psychiatryonline.org/cgi/content/full/51/3/327.

John A. Talbott, M. D., Editor, "1950: The Beginning of a New Era in Mental Health,» Psychiatr Serv 51,7, January 2000, http://ps.psychiatryonline.org/cgi/content/full/51/1/7. Jeffrey L. Geller, M. D., M. P. H., «The Last Half-Century of Psychiatric Services as Reflected in Psychiatric Services,» Psychiatr Serv 51, 41-67, January 2000, http://ps.psychiatryonline.org/cgi/content/full/51/1/41. 
Por outro lado, a década de 50 foi designada pela época da feminilidade. No pós-guerra, sobretudo nos EUA, muitas mulheres deixaram os empregos e regressaram ao lar, casavam cedo e tinham filhos. A mulher dos anos 50, além de bela e bem cuidada, deveria ser boa dona de casa, esposa e mãe. A literatura da época, quer a científica, quer a de outro tipo enfatizava a ideia de que o trabalho tornaria a mulher masculina e, consequentemente, insegura quanto à sua identidade, para além de prejudicar o seu papel de esposa e de mãe. A ausência da mãe desencadearia graves perturbações nos filhos. Assim, a construção da sua identidade sexual enquanto mulher e as funções como mãe constituíam as coordenadas do comportamento feminino e delas dependeria o seu equilíbrio psíquico.

As relações entre ginecologia, obstetrícia e psiquiatria, problemas como a frigidez, a esterilidade, as perturbações psicológicas decorrentes da gravidez, do puerpério e da lactação estavam na ordem do dia, bem assim como os métodos psicoterapêuticos de acompanhamento do parto.

Em França, o debate sobre a sexualidade da mulher voltou a entrar em cena, no cerne do movimento psicanalítico inaugurado por Jacques Lacan e Françoise Dolto, no final da década, culminando com o Congresso de Amesterdão em Setembro de 1960. Debate que fez ressurgir a polémica das décadas 20 e 30 do século XX, em torno das concepções freudianas sobre a sexualidade feminina, o "Continente Negro», segundo a metáfora de Freud. ${ }^{2}$

Em Portugal, na década de 50 também se verificou um surto de estudos sobre as relações entre ginecologia, obstetrícia e psiquiatria, sobre a puberdade, a frigidez, a esterilidade, as perturbações psicológicas decorrentes da gravidez, do puerpério e da lactação, bem assim como acerca dos métodos psicoterapêuticos de acompanhamento do parto.

Segundo Barahona Fernandes, nos anos 50-60 do século XX, e, de acordo com, ocorreu uma expansão científica da psiquiatria portuguesa, nomeadamente com a participação de vários psiquiatras portugueses (Luís Navarro Soeiro, Diogo Furtado, Barahona Fernandes, Pedro Polónio, Seabra-Dinis, Fragoso Mendes e João dos Santos entre outros) no I Congresso Mundial de Psiquiatria, realizado em Paris de 18 a 27 de Setembro de 1950.

À revitalização da psicanálise na Europa a partir do seu sucesso nos Estados Unidos seguiu-se a sua implementação em Portugal. Tal como afirmam Barahona Fernandes e Pedro Luzes até à década de 50 não havia psicanálise no nosso país, mas textos psicanalíticos: «Freud era apenas cultivado literariamente.» ${ }^{3}$

${ }^{2}$ Muriel Djjéribi-Valentin, «Préface», In: Françoise Dolto, Sexualité Féminine, Paris, Gallimard, 1996, pp. 9-41.

${ }^{3}$ Barahona Fernandes, "História e Desenvolvimento no Século XX da Psiquiatria e Psicologia Médica em Portugal,» in História e Desenvolvimento da Ciência em Portugal no Século XX, (Lisboa, Publicaçōes do II Centenário da Academia de Ciências de Lisboa, 1992), p.363. Pedro Luzes, Cem Anos de Psicanálise, Lisboa, Edições ISPA, p. 10. 


\section{Género e patologia}

Passaremos à análise de uma amostra de artigos representativos da teoria e da clínica psiquiátricas em Portugal na década em estudo, procedendo a um levantamento das imagens do comportamento feminino, bem assim como das relações estabelecidas entre género e psicopatologia neles implícitas. ${ }^{4}$

Segundo Barahona Fernandes, a mulher teria menor motivação para os valores objectivos, principalmente na idade madura. Durante grande parte da sua vida as tendências pessoais, subjectivas ocupariam a primazia sobre todas as outras em oposição ao que sucederia com os indivíduos do sexo masculino. ${ }^{5}$

No que diz respeito à maior tendência para sofrer comportamentos do tipo obsessivo compulsivo, Luís Navarro Soeiro afirmou, no artigo "A Psiconevrose Obsessiva,» ${ }^{6}$ que observou uma maior incidência de casos na mulher, referindo que estatisticamente se verificaria uma predilecção pelo sexo feminino. ${ }^{7}$

No artigo em análise, descreveu vários casos clínicos referentes a mulheres e apenas um representativo do sexo masculino. Comentou, a propósito do comportamento sexual das doentes obsessivas: "As mulheres são geralmente frias e devido a bizarrias nas suas relações simpáticas com o mundo que as cerca, sujeitas a todos os caprichos ou abstençôes.» ${ }^{8}$ Por seu turno, os homens procurariam extravagâncias ou fantasias sexuais, feiticistas e sádicas. Ilustrou a componente masoquista do comportamento feminino com a análise do caso de uma paciente.

Por seu turno, Fragoso Mendes, em «Reacções Neuróticas,» ${ }^{9}$ também referiu que as reacções neuróticas de tipo obsessivo se manifestariam mais frequentemente nas mulheres, por vezes logo na infância, puberdade ou adolescência de uma forma episódica ou constante (constituição psicasténica) em personalidades inseguras, anancásticas, meticulosas e escrupulosas com predisposição hereditária dominante. ${ }^{10}$

No que concerne à articulação entre a feminilidade e a maior ocorrência de comportamentos depressivos, há uma série de estudos que estabelecem uma relação quase de causa e efeito entre as características específicas da mulher e a génese das depressōes.

Diogo Furtado, no texto «Sistemática das Depressões e sua Terapêutica,» ${ }^{11}$ aludiu à relação entre menopausa e depressão quando trata da depressão transacional.

\footnotetext{
${ }^{4}$ No artigo "Psicologia dos Estados Passionais», A Medicina Contemporânea, 6, (Junho de 1949), pp. 211-236, Navarro Soeiro delineou algumas das coordenadas que iriam orientar o pensamento psiquiátrico sobre o comportamento feminino, na década seguinte.

${ }^{5}$ Barahona Fernandes, «Perspectivas da Evolução da Personalidade», Jornal do Médico, 849, (1959), p. 13.

${ }^{6}$ Luís Navarro Soeiro, "A Psiconevrose Obsessiva», Anais Portugueses de Psiquiatria, 4, (1952), pp. 141-172.

${ }^{7}$ Navarro Soeiro, op. cit. (6), p.1 56.

${ }^{8}$ Navarro Soeiro, op. cit. (6), p. 154

9 João Fragoso Mendes, «Reacções Neuróticas», Jornal do Médico, 697, (1956), pp. 229-243.

${ }^{10}$ Fragoso Mendes, op.cit. (9), p. 240.

${ }^{11}$ Diogo Furtado, «Sistemática das Depressões e sua Terapêutica», Jornal do Médico, 899, (1960), 845-863 .
} 
A depressão involutiva seria uma afecção acentuadamente mais frequente, sobretudo, na mulher após o climatério, e, segundo este clínico, apresentaria relações muito próximas com as psicoses do ciclo esquizofrénico. A prática clínica teria evidenciado a frequência com que se encontram manifestaçôes do tipo paranóide, ideias delirantes, persecutórias, fenómenos alucinatórios e sentimentos de estranheza, entre outros. Perspectiva similar é apresentada por Luís Navarro Soeiro em «Hereditariedade das Psicoses Endógenas» ${ }^{12}$ :

A predominância da psicose maníaco depressiva ou ciclotímica no sexo feminino é possivelmente devida a uma maior penetrância genética na mulher, sendo esta como é mais sujeita a variaçôes periódicas do humor, com outros ritmos biológicos e metabólicos e, por isso também mais sensível às influências psíquicas exógenas.

Neste sentido Martins Nunes num artigo intitulado «Sobre as Psicoses entre os Nativos de Moçambique» ${ }^{13}$ afirmou que se observariam diferenças entre os sexos, sendo as psicoses involucionais, as infecçôes vasculares cerebrais assim como as psicoses maníaco-depressivas muito mais frequentes no sexo feminino, mas sublinhou que se limitara a constatar um facto sem sugerir hipóteses. ${ }^{14}$ Por seu turno, Victor Fontes escreveu no seu artigo "Alguns Aspectos das Neuroses na Adolescência» ${ }^{15}$ que a anorexia mental seria mais frequente nas raparigas bem assim como as neuroses. $\mathrm{O}$ sistema motor feminino seria mais afectado, sobretudo os membros inferiores mais atingidos com fictícia coordenação motora, dificultando ou mesmo impossibilitando a marcha. A homossexualidade na adolescência seria, em seu entender, igualmente mais frequente entre as raparigas do que entre os rapazes.

A este respeito, João dos Santos afirmou precisamente o contrário no texto «Neuroses da Infância.» ${ }^{16}$ Aí declarou que a sexualidade física na adolescente era menos bem aceite do que no rapaz e, por consequência, o desvio do desejo sexual sublimar-se-ia mais nas raparigas. Seria muito menos frequente a adolescente cair na prática sexual, tanto no sentido auto, como homossexual. O vício sexual na rapariga resultaria sobretudo do seu eventual abandono moral ou da sede de luxo e do prazer decorrentes da vida mundana. Continuou dizendo que tinha a impressão de que se a adolescente não recebesse em troca das práticas sexuais viciosas compensações materiais resistiria mais à neurose sexual do que o adolescente.

No texto "Psicanálise e Tratamento das Depressōes,» ${ }^{17}$ Francisco Alvim defendeu que a rapariga adolescente passaria por uma série de problemas como a fobia das

\footnotetext{
${ }^{12}$ Luís Navarro Soeiro, «Hereditariedade das Psicoses Endógenas», Separata do Boletim Clinico dos Hospitais Civis de Lisboa, 1 e 2, (1956), p. 148

${ }^{13}$ Martins Nunes, «Sobre as Psicoses entre os Nativos de Moçambique», Anais Portugueses de Psiquiatria, 12, (1960), 3-36.

${ }^{14}$ Martins Nunes, op.cit. (13), pp. 13, 14, 15 e 25.

${ }^{15}$ Victor Fontes, "Alguns Aspectos das Neuroses na Adolescência», Anais Portugueses de Psiquiatria, 4, (1952), pp. 112-128.

${ }^{16}$ João dos Santos, "Neuroses da Infância», Anais portugueses de Psiquiatria, 4, (1952), pp. 95-111.

${ }^{17}$ Francisco Manuel Barreto Alvim, «Psicanálise e Tratamento das Depressōes», Separata do Jornal do Médico, 42, (1960), pp. 600-601.
} 
regras, a anorexia mental, que gradualmente redundaria em frigidez, esterilidade, reacções infantis ao meio e na menopausa depressóes das mais graves o mesmo é dizer melancolia involutiva. ${ }^{18}$

No «Curso de Psicologia Médica,» ${ }^{19}$ Barahona Fernandes explicou que a exaltação de uma mulher com os seus familiares durante a distimia pré-menstrual denunciaria um fundo de labilidade biológica e alteração do tónus vital, e que situação idêntica se verificaria nos estados de exaltação da menopausa, da involução senil, dependentes, sobretudo, do fundo orgânico alterado. Todavia, relevou que a psicogénese seria sempre condicionada por outros factores, personalidade/organicidade/sociedade. ${ }^{20}$

As cefaleias de etiologia psicológica também seriam mais frequentes nas mulheres do que nos homens. Neste sentido, Diogo Furtado, “Cefaleias Psicogénias» ${ }^{21}$ declarou: «Em primeiro lugar a cefaleia psicogénia é particularmente mais frequente nas mulheres, muito mais que nos homens. Aproximadamente $65 \%$ dos casos da estatística americana eram mulheres.» 22 Pedro Luzes no artigo «Enxaquecas,» ${ }^{23}$ incluído na mesma separata, afirmou também: "As relaçôes entre os factores endócrinos e as enxaquecas são demonstradas por várias observaçôes clínicas. Assim as crises atingem sobretudo as mulheres. Começam muitas vezes na puberdade e são frequentemente síncronas com a menstruação, cessam em geral durante a gravidez ou menopausa».

Quanto às teorias que explicariam estes factos de observação, Pedro Luz afirmou que seriam várias. Alguns autores apontariam em primeiro lugar para a disfunção dos ovários, considerando a enxaqueca como efeito de uma hipo ou hipersecção ovárica. Outros sustentariam que a função ovárica seria secundária na génese da enxaqueca, a causa principal localizar-se-ia na hipófise. ${ }^{24}$

Para concluirmos, citamos João Fragoso Mendes que na sua tese de doutoramento Psicoses Sintomáticas. Estudo Clínico e Análise Estrutural de 509 Casos, ${ }^{25}$ afirmou o seguinte sobre a predisposição das mulheres para serem afectadas pelas psicoses sintomáticas, sobretudo as de natureza confusional: ${ }^{26}$

${ }^{18}$ Francisco Alvim, op. cit. (17) p. 600.

${ }^{19}$ Barahona Fernandes, "Curso de Psicologia Médica. Introdução, Problemas Gerais das Neuroses, Análise Convergente», Anais Portugueses de Psiquiatria, 4, (1952), pp. 14-38.

${ }^{20}$ Barahona Fernandes, op. cit. (19), p. 31. Neste artigo procedeu à análise de diferentes casos clínicos de mulheres, entre os quais destacou o de uma mulher, filha de pai leviano e mãe severa, que teria descoberto o amor aos 40 anos. Por não conseguir assumir tal sentimento sofria e sentia por isso profunda angústia

${ }^{21}$ Diogo Furtado, «Cefaleias Psicogénias», Separata de O Médico, 88, (1955), pp. 47-53.

22 Diogo Furtado, op. cit. (21), p. 48.

${ }^{23}$ Pedro Luzes, «Enxaquecas», Separata de O Médico, 88, (1955), pp. 35-43.

${ }^{24}$ Pedro Luzes, op. cit. (23), p. 39.

${ }^{25}$ João Fragoso Mendes, Psicoses Sintomáticas. Estudo Clínico e Análise Estrutural de 509 Casos, (Lisboa, Edição do Autor, 1959).

26 João Fragoso Mendes, op. cit. (25), pp.82 e 88. Destacamos também dois artigos que focam outra dimensão da etiologia das disfunçôes femininas, atribuindo as causas das neuroses a uma reacção defensiva da mulher às ameaças do meio à sua integridade física e psíquica. Um é de Diogo Furtado, "Um Estranho Caso de Histeria» Furtado, Diogo Guilherme da Silva Alves, "Um Estranho Caso de Histeria», Jornal do 
Nesta predisposição para as psicoses sintomáticas - não só a idade mas também o sexo desempenha um papel a considerar, mostrando as mulheres mais susceptibilidade do que os homens. Atribui-se esta tendência a vários factores, como a menstruação, climatério, gravidez, puerpério e lactação. Estas fases de comprovada labilidade psíquica parecem facilitar a eclosão de psicoses sintomáticas, mais fácil ainda quando surgem factores exógenos suficientemente intensos que mobilizem uma tendência latente. (...) Aceitamos que as psicoses sintomáticas em geral, e muito particularmente os síndromas confusionais, são mais frequentes nas mulheres.

Como veremos, seguidamente, as relações entre género e patologia tornam-se mais explícitas nos textos que focam as ligações entre disfunções ginecológicas e psicopatologia.

\section{Ginecologia e Psiquiatria}

A propósito das ligações intrínsecas entre Ginecologia e Psiquiatria, no seu artigo «Reacções Neuróticas em Ginecologia», ${ }^{27}$ Barahona Fernandes começa por referir que desde a Antiguidade existia especial interesse pela interacção entre o psiquismo e as doenças do aparelho genital feminino. Em seu entender, não seria necessária grande "penetração psicológica para compreender as repercussôes» das fases cruciais da vida da mulher, puberdade, menstruação, actividade sexual, gravidez, parto, lactação menopausa na formação da sua personalidade. Afirmou que as doenças ginecológicas, na medida em que interferem nestas funções, e alteram ou impedem o desempenho do papel feminino na vida conjugal, na família e na sociedade se reflectirão, mais fortemente, no comportamento da mulher. Igualmente evidentes seriam as consequências de muitos conflitos e episódios emocionais nas funções sexuais da mulher. Barahona Fernandes delineou um quadro dos «tipos sindromáticos mais comuns de reacção de reacção neurótica» na área da ginecologia. Segundo o referido clínico, a experiência tradicional, a intuição, a sensatez e o saber dos ginecologistas careceriam de ser completados pelo estudo das complexas relações psicossomáticas. ${ }^{28}$

Em consonância com Barahona Fernandes, Luís Navarro Soeiro afirmou em «Factores Psicológicos e Esterilidade» ${ }^{29}$ que desde o século anterior o ginecologista, dada a natureza da sua especialidade e devido a certos exageros cirúrgicos, teria sido alvo da crítica dos psiquiatras, até porque «à consulta do ginecologista acorreriam talvez tantas neuróticas e psicopatas como à do psiquiatra...» e este poderia «correr o

Médico, 639, (1955), 993-995, e o outro é da autoria de Amílcar Moura «Terapêutica Psicossomática Convergente.» Separata do Jornal Médico, 27, (1955), pp. 1-18.

${ }_{27}$ Barahona Fernandes, «Reacçōes Neuróticas em Ginecologia» Separata do Jornal do Médico, 539, (1953), pp. 3-29.

${ }^{28}$ Barahona Fernandes, op. cit. (27), p. 5.

${ }^{29}$ Luís Navarro Soeiro, «Factores Psicológicos e Esterilidade», Anais Portugueses de Psiquiatria, 9, (1957), pp. 90-100. 
risco de ficar inexoravelmente detido na barreira dos orgãos genitais.» ${ }^{30}$ A gravidez, o puerpério ${ }^{31}$ e até os períodos menstruais gerariam muitos quadros de perturbaçóes psíquicas, particularmente graves. ${ }^{32}$

De acordo com Navarro Soeiro, notar-se-ia em toda a neurótica uma perturbação da sensibilidade enteroceptiva, da cinestesia visceral, nomeadamente da sensibilidade pélvico genital e a doente, "escolheria, por assim dizer, o órgão sobre o qual descarregaria a emoção do conflito, (histeria da conversão segundo a terminologia de Freud). ${ }^{33}$ Aqui se poderia encontrar a etiologia de muitos dos casos de amenorreia, vaginismo, frigidez, esterilidade, entre outros. Navarro Soeiro mostra-se convicto que muitas das doentes que consultariam o ginecologista padeceriam de neurose, neurose essa que exprimiria um conflito de uma personalidade predisposta para um certo tipo de reacção anormal no meio familiar e onde estaria inserida. Diz-se convicto que a grande maioria das frígidas são neuróticas e que a frigidez tem repercussões negativas na fecundidade. ${ }^{34}$ Barahona Fernandes sublinhou também que a grande histeria teria sido substituída, na altura, pelas afecçôes psicossomáticas, caso das amenorreias das trabalhadoras ou das mobilizadas. ${ }^{35}$

Eduardo Cortesão em «Psicodinamia e Tratamento da Frigidez na Situação Grupoanalítica» ${ }^{36}$ procedeu a uma abordagem psicanalítica das causas da frigidez, preconizando que o principal conflito na frigidez psicogénea consistiria na repressão da atracção sexual infantil para com o pai e rivalidade e culpa em relação à mãe. Em seu entender, na situação terapêutica de grupo o terapeuta assumiria um papel de figura materna e o grupo, no seu todo, o papel de uma figura materna. ${ }^{37}$

A propósito, Barahona Fernandes alertou para a predisposição frequente de proceder-se a interpretações psicanalíticas das reacções neuróticas e das ginecopatias. Chamou também a atenção para o cuidado que se deveria ter na avaliação etiológica das doenças e para a necessidade de abandonar posições unilaterais. Deveria assim ter-se em conta uma pluralidade de factores na formação das patologias. Será no equilíbrio entre tendências e na compreensiva colaboração entre o ginecologista e o psicoterapeuta que estaria a solução para a compreensão e tratamento das doentes. ${ }^{38}$ Quer Barahona

${ }^{30}$ Navarro Soeiro, op. cit. (29), p. 90.

31 Ver Pedro Polónio; Motta Figueiredo, "As Psicoses da Gravidez, Puerpério e Lactação», Anais Portugueses de Psiquiatria, pp. 112, 4, (1954).

32 Navarro Soeiro, op. cit. (29), p. 93.

33 Ibid

${ }^{34}$ Navarro Soeiro, op.cit. (29), pp. 93-94. No mesmo texto, Navarro Soeiro interrogou-se sobre o que representaria de sofrimentos inúteis para uma sensibilidade insegura, expressôes ou diagnósticos como útero caído e metrite, na medida em que muitas vezes a metrite não seria necessariamente inflamatória, mas poderia resultar de uma hiperemia repetida por excitação vasomotora que acompanharia a insatisfação da libido, caso a excitação erótica não fosse seguida de orgasmo.

35 Barahona Fernandes, op. cit. (27), pp. 12-13.

${ }^{36}$ Eduardo Cortesão, "Psicodinamia e Tratamento da Frigidez na Situação Grupo-analítica», Jornal do Médico, 468, (1960), pp. 202-203.

37 Eduardo Cortesão, op.cit. (36), pp. 202-203.

${ }^{38}$ Barahona Fernandes, op. cit. (27), pp. 16-25. 
Fernandes, quer Navarro Soeiro preconizaram a necessidade de colaboração e mútuo esclarecimento entre os ginecologistas e os psicoterapeutas. ${ }^{39} \mathrm{Na}$ prática, seriam possíveis os dois erros: interpretarem-se os dados psicológicos como consequência de uma doença local e, prolongar, sem êxito, os tratamentos tópicos, ou considerarem-se os sintomas neuróticos como psicogéneos e diagnosticar uma doença nervosa desencadeada por disfunções emocionais, omitindo a dimensão fisiológica. ${ }^{40}$

\section{Conclusões}

Em suma, o sexo feminino é retratado, na generalidade dos artigos de psiquiatria publicados por especialistas portugueses nas décadas de 50 e 60, como sendo mais predisposto do que o masculino, a sofrer perturbaçôes do foro psicológico devido ao carácter mais emotivo da sua vida interior, à especificidade dos seus ciclos biológicos, sexualidade e funções reprodutivas. A menarca, a menstruação, o puerpério, o aleitamento e a menopausa constituiriam momentos propícios ao aparecimento de perturbações comportamentais. As mulheres estariam assim condicionadas pelas suas características biológicas. Adoptariam comportamentos tendencialmente mais masoquistas do que os homens, seriam mais atreitas às cefaleias de etiologia psíquica, à depressão, ao ciúme, ao ressentimento e aos comportamentos obsessivo compulsivos. Evidenciariam ainda maior susceptibilidade às psicoses sintomáticas, nomeadamente os sintomas confusionais ocorreriam sobretudo no sexo feminino. Um outra conclusão a retirar é que, dada a estreita correlação entre as funções sexuais femininas e o comportamento da mulher, tornar-se-ia indispensável a colaboração entre ginecologistas e psiquiatras, até porque os ginecologistas sempre teriam adoptado atitudes em que a consideração de factores psicossomáticas estiveram presentes, sem que disso se apercebessem.

\footnotetext{
${ }^{39}$ Barahona Fernandes, op. cit. (27), pp. 16-25 e Navarro Soeiro, op. cit. (29), pp. 93-94.

40 Barahona Fernandes, op. cit. (27), pp. 18.
} 
(Página deixada propositadamente em branco) 


\section{Colecçãa \\ 2 Ciências e Culturas Caimbra 2006}

